\title{
Awareness of Glaucoma and Associated Factors Among Adults in Gish Abay Town, Northwest Ethiopia
}

This article was published in the following Dove Press journal: Clinical Optometry

\author{
Zewdu Yenegeta Bizuneh (D)' \\ Ayanaw Tsega (iD ${ }^{2}$ \\ Yezinash Addis ${ }^{2}$ \\ Fisseha Admassu ${ }^{3}$ \\ 'Department of Ophthalmology, St. Paul's \\ Hospital Millennium Medical College, \\ Addis Ababa, Ethiopia; ${ }^{2}$ Department of \\ Optometry, College of Medicine and \\ Health Sciences, University of Gondar, \\ Gondar, Ethiopia; ${ }^{3}$ Department of \\ Ophthalmology, College of Medicine and \\ Health Sciences, University of Gondar, \\ Gondar, Ethiopia
}

Purpose: The purpose of this study was to determine the awareness of glaucoma and associated factors among adults living in Gish Abay town, Northwest Ethiopia.

Methods: A population-based cross-sectional study was conducted on 594 adults who were selected using systematic random sampling from April to May 2018. Data were entered into Epi Info version 7 and were analyzed by SPSS version 23. Binary and multivariable logistic regression was used to determine factors associated with awareness. Variables with $P$-value $<0.05$ were considered statistically significant.

Results: The proportion of awareness of glaucoma was $24.4 \%$ [95\% CI; 21.0, 28.1]. It was positively associated with educational status, primary education [AOR: 3.15; 1.72, 5.77], secondary education [AOR; 3.11: 1.66, 5.84], college and above [AOR; 6.10; 2.80, 13.27], history of eye examination [AOR: 6.52; 3.46, 12.25], income level $>2000$ Ethiopian birr $[4.65 ; 2.59,8.37]$ and history of chronic diseases [AOR; 2.93: 1.25, 6.85].

Conclusion: The status of glaucoma awareness in Gish Abay town can be said to be low as compared to studies. Higher educational status, eye examination, history of chronic diseases and better income level were significantly associated with awareness of glaucoma.

Keywords: awareness, glaucoma, Gish Abay, Ethiopia

\section{Introduction}

Glaucoma is a group of diseases characterized by progressive optic neuropathy which may be asymptomatic in the majority or may result in symptoms like diminished vision and loss in the visual field. ${ }^{1}$

Globally, $15 \%$ of blindness is due to glaucoma and about 600,000 people go blind annually. ${ }^{2}$ Africa accounts for $15 \%$ of the world's blindness burden due to glaucoma. ${ }^{3}$ It is the fifth common cause of blindness in Ethiopia which results in irreversible sight loss for 62,000 adults. ${ }^{4,5}$

Glaucoma is the leading cause of irreversible blindness in the world. Yet, because glaucoma is a slowly progressive disease, often with few noticeable symptoms, about half of affected individuals are unaware of the disease. ${ }^{6}$ As such, they do not seek adequate care. It had been estimated that half of glaucoma patients were already blind in at least one eye upon their presentation at health institutions in Africa. ${ }^{7}$ The situation is worse in sub-Saharan Africa, where it is further compounded by poor awareness in the region. ${ }^{8}$ Many people assume that the presence of glaucoma would be heralded by symptoms and therefore they underestimate the serious nature of this insidious disease. ${ }^{9}$
Correspondence: Zewdu Yenegeta Bizuneh

Department of Ophthalmology, St. Paul's Hospital Millennium Medical College, Swazilland Street, P.O. Box: 127I, Addis Ababa, Ethiopia

Tel +251913416492

Email zewduyenegeta@gmail.com 
Glaucoma represents a major public health challenge in the aging population as it is the second largest cause of preventable blindness in the world. ${ }^{10}$ The increasing prevalence of glaucoma is expected to cause a significant economic burden and poor quality of life.

Glaucoma is believed to negatively influence the quality-of-life of affected individuals. Patients with glaucoma who live in a developing country have less functional status than non-glaucomatous patients. The constant fear of going blind and the need for continuous therapy can physically and emotionally interfere with one's life, ${ }^{11}$ and the impact of sight loss has negative implications not only for the person affected but also for society as a whole. ${ }^{12}$

Prompt diagnosis before significant visual loss requires the presence of a high level of public awareness about glaucoma and a culture of routine eye examination to increase early case detection. ${ }^{13}$ These are both absent in Ethiopia.

Improved awareness and better perception can positively influence the accuracy of eye health education and are key to the development of a positive outlook. A positive outlook can motivate patients to ensure that family members undergo glaucoma screening regularly, thereby enhancing prompt diagnosis and reducing the risk of blindness from glaucoma. It can also improve adherence and persistence to treatment and follow-up in patients. ${ }^{13}$

Creating public awareness of glaucoma and its risk factors is essential to increase participation in screening programs and possible treatment, ${ }^{14}$ thereby reducing its devastating consequences. Contrary to this, lack of awareness appeared to influence self-care practices negatively. ${ }^{15}$

Increased awareness can change the social perceptions of ocular health and influence people to participate in regular ophthalmic screening. ${ }^{1}$ Published evidence indicates that the late diagnosis of glaucoma is an important risk factor for subsequent blindness and is associated with poor knowledge about the condition. ${ }^{10}$ Assessment of awareness is thus the first step in planning disease management. ${ }^{16}$ Therefore, the purpose of this study was to determine the proportion of awareness of glaucoma and its associated factors in the study area.

\section{Methods}

\section{Study Setting and Population}

A population-based cross-sectional study was conducted in Gish Abay town on 602 adults from April to May 2018. Gish Abay town, which is located $463 \mathrm{~km}$ from Addis
Ababa, is the capital of Gish Abay in West Gojjam administrative zone. All adults $\geq 18$ years were included in the study.

\section{Sample Size Determination}

The entire sample size for awareness of glaucoma by taking a proportion of awareness of glaucoma $p=35.1^{17}$ was 602 , which was determined using the single population proportion formula with the assumption of a $95 \%$ confidence interval $(Z \alpha / 2=1.96), 4 \%$ margin of error (w) and 10\% non-response rate (Appendix 1).

\section{Sampling Procedure}

A systematic random sampling technique was used to select households using the sampling fraction. The sampling fraction was determined by taking the ratio of households (8883) to the sample size, i.e. 14. Finally, one eligible adult was selected from each household using a simple random sampling/lottery method if more than one adult was living in the house.

\section{Data Collection Tool and Procedure}

A structured questionnaire adapted from previously published studies ${ }^{1,10,16-20}$ was utilized. It was initially prepared in English, translated into Amharic (local language) and re-translated into English to check consistency in the meaning of words and concepts. The questionnaire included background information, clinical characteristics and questions to measure awareness of glaucoma (Appendix 1). The data were collected through face-to-face interviews by five trained BSc optometrists.

\section{Operational Definition}

Awareness was measured when a participant responded "yes" to the question "have you ever heard of glaucoma" and chose at least one answer among the alternatives which explains the condition as "glaucoma is high eye pressure", "glaucoma is high eye pressure causing blindness", "glaucoma causes damage to the eye nerve", "blinding eye disease causing eye nerve damage, eye disease causing visual field loss" 18 or similar answers when asked. In this study, hearing of glaucoma alone was not considered as awareness because merely being aware of the term did not ensure awareness about the disease. A previous study on a similar topic in Ethiopia $^{18}$ and the pre-test procedure of this study indicated that participants who said "Yes" for the question "have you ever heard of glaucoma?" actually meant 
"trachoma", probably because they have the same suffixes "-oma".

\section{Data Management and Analysis}

After checking for clarity and completeness, data were entered into Epi Info 7 and exported into statistical package for social science/SPSS version 23 for analysis. Both descriptive and analytical methods were employed for analysis. The descriptive parts of the data were summarized using measures of central tendency and dispersion.

A binary logistic regression model was used to identify factors which were associated with glaucoma awareness. Variables were fitted into the model using the enter method. Hosmer and Lemeshow model fitness was checked. Multi-collinearity between the independent variables was also checked by tolerance and variance inflation factor (VIF). The adjusted odds ratio with $95 \%$ confidence interval was used to identify the significant factors. Variables with $p$-value less than 0.05 were considered statistically significant.

\section{Results}

A total of 594 adults participated with a response rate of $98.7 \%$. The median (IQR) age was $28(22-45)$ years. About $308(51.9 \%)$ of the respondents were females. A majority $359(60.4 \%)$ of the participants had no formal education (Table 1).

About 43 (7.2\%) adults had chronic diseases, either diabetes mellitus or hypertension or both, and around 74 $(12.5 \%)$ adults had history of eye examination at least once in their life. Twenty-four (4\%) adults had positive family history of glaucoma and about $10(1.7 \%)$ of the participants had positive history of glaucoma.

One hundred and ninety-two $(32.3 \%)$ of the participants had heard of glaucoma. However, only 145 (24.4\%) [95\% CI: 21.0, 28.1] of them were aware of glaucoma.

In the multivariable analysis after adjusting for age, sex and ethnicity: history of eye examination, educational status, level of income and positive history of chronic diseases, either diabetes mellitus or hypertension or both, were significantly associated with awareness of glaucoma.

The odds of being aware of glaucoma among adults with primary education [AOR: 3.15 ; 95\% CI: 1.72, 5.77] and secondary education [AOR; 3.11, 95\% CI: 1.66, 5.84] were three times greater than among those without formal education. Similarly, the odds of being aware of glaucoma among adults who had college and above education were
Table I Socio-Demographic and Socio-Economic Characteristics of the Study Participants in Gish Abay Town, Northwest Ethiopia, June $2018(n=594)$

\begin{tabular}{|c|c|c|}
\hline Characteristics & Frequency & Percentage \\
\hline \multicolumn{3}{|l|}{ Sex } \\
\hline Female & 308 & 51.9 \\
\hline Male & 286 & 48.1 \\
\hline \multicolumn{3}{|l|}{ Age (years) } \\
\hline $18-22$ & 169 & 28.5 \\
\hline $23-27$ & 144 & 24.2 \\
\hline $28-45$ & 140 & 23.6 \\
\hline$\geq 46$ & 141 & 23.7 \\
\hline \multicolumn{3}{|l|}{ Religion } \\
\hline Orthodox & 586 & 98.7 \\
\hline Others* & 8 & 1.3 \\
\hline \multicolumn{3}{|l|}{ Ethnicity } \\
\hline Amhara & 584 & 98.3 \\
\hline Oromo & 10 & 1.7 \\
\hline \multicolumn{3}{|l|}{ Level of Education } \\
\hline No formal education & 359 & 60.4 \\
\hline Primary education & 101 & 17.0 \\
\hline Secondary education & 90 & 15.2 \\
\hline College and above & 44 & 7.4 \\
\hline \multicolumn{3}{|l|}{ Marital Status } \\
\hline Single & 275 & 46.3 \\
\hline Married & 288 & 48.5 \\
\hline Divorced & 14 & 2.4 \\
\hline Widowed & 17 & 2.9 \\
\hline \multicolumn{3}{|l|}{ Type of Occupation } \\
\hline Farmer & 156 & 26.3 \\
\hline Government employee & 48 & 8.1 \\
\hline Merchant & 185 & 31.1 \\
\hline Housewife & 72 & 12.1 \\
\hline Job seeker & 64 & 10.8 \\
\hline Others** & 69 & 11.6 \\
\hline \multicolumn{3}{|l|}{ Monthly Income (ETB) } \\
\hline$\leq 750$ & 298 & 50.2 \\
\hline $751-1300$ & 115 & 19.4 \\
\hline$|30|-2000$ & 62 & 10.4 \\
\hline$\geq 2001$ & 119 & 20 \\
\hline
\end{tabular}

Notes: Others*=Muslim and Catholic. Others**=students, driver and religious leader

about six [AOR; 6.10, 95\% CI: 2.80, 13.27] times greater than their counterparts.

The odds of glaucoma awareness among adults with history of eye examination were 6.5 [AOR: $6.52,95 \%$ CI: $3.46,12.25]$ times greater than their counterparts.

The odds of being aware of glaucoma among adults with positive history of chronic diseases, either diabetes 
mellitus or hypertension or both, were nearly three [AOR; $2.93,95 \%$ CI: $1.25,6.85]$ times greater as compared to their counterparts.

Furthermore, the odds of being aware of glaucoma among adults with higher income level ( $\geq 2001$ ETB) were 4.6 [AOR; 4.65, 95\% CI: 2.59, 8.37] times greater than those adults with lower income levels (Table 2).

\section{Discussion}

The proportion of awareness of glaucoma was $24.4 \%$ (95\% CI: 21.0, 28.1). This finding is lower than the reports from Gondar, Northwest Ethiopia (35.1\%) ${ }^{17}$ and Addis Ababa (28.4\%), Central Ethiopia. ${ }^{20}$ This might be due to the differences in educational status between the study participants. The study in Gondar showed that only $32.7 \%$ of adults had no formal education whereas in this study more than half $(60.2 \%)$ of adults had no formal education. From previous studies, educational status is the significant predictor for awareness of glaucoma. 7,10,14,17,20,21

This finding is also lower than the reports from Ghana $(39.3 \%),{ }^{22}$ Nepal (60.6\%), ${ }^{14}$ Puducherry, India (45\%), ${ }^{1}$ Tehran, Iran (46.6\%), ${ }^{23}$ Birmingham, UK (67\%) ${ }^{24}$ and Philadelphia, USA $(73 \%){ }^{7}$ This might be due to differences in socio-demographic and socio-economic status, and participants from developed countries (UK, USA) will access or utilize eye care services easily and will be occupied by health insurance. ${ }^{15}$ The other possible explanation for this discrepancy might be that the way we measure awareness is quite different. For the above studies a participant was said to be aware of glaucoma if the

Table 2 Factors Associated with Awareness of Glaucoma Among Adults in Gish Abay Town, Northwest Ethiopia, June 20I8 ( $\mathrm{n}=594$ )

\begin{tabular}{|c|c|c|c|c|}
\hline \multicolumn{5}{|c|}{ Awareness of Glaucoma } \\
\hline Variables & Yes & No & COR $(95 \% \mathrm{Cl})$ & AOR $(95 \% \mathrm{Cl})$ \\
\hline \multicolumn{5}{|l|}{ Age Category (years) } \\
\hline $18-22$ & 35 & 134 & 1.00 & 1.00 \\
\hline $23-27$ & 43 & 101 & $\mathrm{I} .63(0.97,2.73)$ & $1.27(0.70,2.29)$ \\
\hline $28-45$ & 45 & 95 & I.8I $(1.08,3.03)$ & $1.60(0.85,3.02)$ \\
\hline$\geq 46$ & 22 & 119 & $0.70(0.39,1.27)$ & $0.57(0.25,1.28)$ \\
\hline \multicolumn{5}{|l|}{ Sex } \\
\hline Male & 84 & 202 & 1.00 & 1.00 \\
\hline Female & 61 & 247 & $0.59(0.41,0.86)$ & $0.79(0.50,1.25)$ \\
\hline \multicolumn{5}{|l|}{ Educational Status } \\
\hline No formal education & 56 & 303 & 1.00 & 1.00 \\
\hline Primary education & 32 & 69 & $2.50(1.5 I, 4.16)$ & $3.15(1.72,5.77)^{* * *}$ \\
\hline Secondary education & 33 & 57 & $3.13(1.87,5.24)$ & $3.11(1.66,5.84)^{* * * *}$ \\
\hline College and above & 24 & 20 & $6.49(3.36,12.54)$ & $6.10(2.80,13.27)^{* * *}$ \\
\hline \multicolumn{5}{|l|}{ Ethnicity } \\
\hline Amhara & 140 & 444 & 1.00 & 1.00 \\
\hline Oromo & 5 & 5 & $3.17(0.90,11.11)$ & $0.62(0.12,3.20)$ \\
\hline \multicolumn{5}{|l|}{ Income Level (ETB) } \\
\hline$\leq 750$ & 34 & 264 & 1.00 & 1.00 \\
\hline $751-1300$ & 35 & 80 & $3.39(1.99,5.79)$ & $2.44(1.34,4.43)^{* *}$ \\
\hline $130 \mid-2000$ & 21 & 41 & $3.97(2.10,7.5 \mathrm{I})$ & $3.50(1.73,7.06)^{* *}$ \\
\hline$\geq 200$ I & 55 & 64 & $6.67(4.01,11.08)$ & $4.65(2.59,8.37)^{* * *}$ \\
\hline \multicolumn{5}{|l|}{ Eye Examination } \\
\hline No & 98 & 422 & 1.00 & 1.00 \\
\hline Yes & 47 & 27 & $7.49(4.44,12.63)$ & $6.52(3.46,12.25)^{* * * *}$ \\
\hline \multicolumn{5}{|l|}{ Chronic Diseases } \\
\hline No & 121 & 430 & 1.00 & 1.00 \\
\hline Yes & 24 & 19 & $4.48(2.37,8.46)$ & $2.93(1.25,6.85)^{*}$ \\
\hline
\end{tabular}

Notes: ${ }^{*} p \leq 0.05 ; * * p \leq 0.01 ; * * * p \leq 0.001 ; 1.00=$ reference.

Abbreviations: $\mathrm{Cl}$, confidence interval; $\mathrm{COR}$, crude odds ratio; $\mathrm{AOR}$, adjusted odds ratio. 
participant had only heard of glaucoma, whereas in this study after they had heard of glaucoma the participant must give at least one possible and plausible explanation which defines the condition.

However, the current level of glaucoma awareness is better as compared to the report from Agaro town in Jimma (2.4\%), Southwest Ethiopia. ${ }^{18}$ This might be due to the age difference among study participants. In the later study, the participants had an average age of 54.5 years as compared to 28 years in this study. Previous studies showed that older age demonstrated less awareness of glaucoma. 1,7,17,20,25

This finding is also higher than reports from Ghana $(3.6 \%),{ }^{26}$ Nepal $(2.43 \%),{ }^{27}$ urban India $\left(13.5 \%{ }^{10}\right.$ and $\left.2.3 \%{ }^{28}\right)$ and rural parts of India $\left(0.32 \%^{29}\right.$ and $\left.8.3 \%{ }^{16}\right)$. This might be the age difference among study participants: 50 years in Ghana, ${ }^{26} 55$ years in Nepal, ${ }^{27} 54$ years in urban Chennai ${ }^{10}$ but 28 years in this study.

On the other hand, the finding of the present study is in line with studies from Ebonyi state, Nigeria $(21.1 \%)^{19}$ and Switzerland $(24.7 \%){ }^{30}$ This might be due to the same study setting. This could also be because the age difference of the respondents was almost similar (28 vs 31 years).

Higher educational status was found to be an important factor for awareness of glaucoma. This was supported by different literature. $7,10,17,20,21,26$ This might be because health-related information transmission is higher as educational status increases ${ }^{1,20,31-33}$ and similarly educated adults do self-reading on personal health-related materials. ${ }^{17}$ This might be also due to educated adults seeking modern medicines as their first choice whereas those adults without formal education need it last after they tried traditional medicines and failed, which in turn affects their level of awareness.

History of eye examination was another important factor found for awareness of glaucoma. ${ }^{7,17,21}$ This might be due to the fact that adults coming for eye examination will attend health education programs and will familiarize themselves with the condition.

Adults with positive history of chronic diseases, either diabetes mellitus or hypertension or both, were positively associated with awareness of glaucoma. ${ }^{1}$ This might be due to the fact that this portion of adults have regular eye check-ups which in turn helps them to familiarize with the disease.

Better income level was also found to be an important determinant for awareness of glaucoma. 1,17,25,26,29,31,33
This might be because adults with higher levels of income can afford and seek medical attention more than their counterparts.

In general, the proportion of awareness in this town was low compared to other studies. The reasons for such a low level of awareness were there were no ophthalmic professionals in the town, and no government sponsored programs to overcome this. Therefore, it is highly recommended to start regular health education campaigns especially in such rural parts of the country.

\section{Conclusion}

About one-fourth of adults were aware of glaucoma and it was low. Higher educational status, eye examination at least once in life, positive history of chronic diseases, either diabetes mellitus or hypertension or both, and higher income level were positively associated with awareness of glaucoma.

\section{Ethics Approval and Consent to Participate}

Ethical clearance was obtained from University of Gondar Ethical Review Committee and a letter of permission was obtained from Gish Abay Administrative Office. Permission was also gained from each household head before contacting study participants. Written informed consent was obtained from each study participant. This study was conducted in accordance with the Declaration of Helsinki.

The study participants were informed about the purpose of the study and their right to refuse and withdraw from the study at any time. Confidentiality was also maintained by excluding identifiers and using codes. Glaucoma-related information was given orally for all study participants after completion of the interview.

\section{Data Sharing Statement}

The dataset used and/or analyzed during this study are available from the corresponding author upon a reasonable request from $\mathrm{Mr}$ Zewdu Yenegeta (contact address: zewduyenegeta@gmail.com).

\section{Acknowledgments}

We would like to acknowledge all participants of the study who kindly volunteered to answer the interview. Our gratitude also goes to data collectors for their tireless work during data collection. 


\section{Author Contributions}

All authors contributed equally to data analysis, drafting or revising the article, gave final approval of the version to be published, and agree to be accountable for all aspects of the work.

\section{Disclosure}

We, the authors, declare no competing interests.

\section{References}

1. Muthu KV, Baba D, Rathna K, Natarajan S, Divya S. Prevalence of awareness and knowledge of glaucoma in urban Puducherry. Sch J App Med Sci. 2015;3(7B):561-567.

2. WHO. Global data on visual impairment Geneva. World Health Organization; 2012 [updated 21; cited 10, 2018]. Available from: http://www.who.int/about/licensing/copyright_form/en/index.html. Accessed February 20, 2020.

3. Tham YC, Li X, Wong TY, Quigley HA, Aung T, Cheng CY. Global prevalence of glaucoma and projections of glaucoma burden through 2040: a systematic review and meta-analysis. Ophthalmology. 2014;121(11):2081-2090. doi:10.1016/j.ophtha.2014.05.013

4. Berhane Y, Worku A, Bejiga A, et al. Prevalence and causes of blindness and low vision in Ethiopia. Ethiop J Health Dev. 2007;21 (3):204-210.

5. Giorgis AT. Raising public awareness of glaucoma in Ethiopia. Community Eye Health J. 2012;25:46.

6. Tielsch JM, Sommer A, Katz J, Royall RM, Quigley HA, Javitt J. Racial variations in the prevalence of primary open-angle glaucoma. The Baltimore eye survey. JAMA. 1991;266:369-374. doi:10.1001/ jama.1991.03470030069026

7. Altangerel U, Nallamshetty HS, Uhler T, et al. Knowledge about glaucoma and barriers to follow-up care in a community glaucoma screening program. Can J Ophthalmol. 2009;44(1):66-69. doi:10. 3129/i08-175

8. Kyari F, Abdull MM, Bastawrous A, Gilbert CE, Faal H. Epidemiology of glaucoma in sub-saharan Africa: prevalence, incidence and risk factors. Middle East Afr J Ophthalmol. 2013;20 (2):111-125. doi:10.4103/0974-9233.110605

9. Pfeiffer N, Krieglstein GK, Wellek S. Knowledge about glaucoma in the unselected population: a German survey. J Glaucoma. 2002;11 (5):458-463. doi:10.1097/00061198-200210000-00016

10. Sathyamangalam RV, Paul PG, George R, et al. Determinants of glaucoma awareness and knowledge in urban Chennai. Indian J Ophthalmol. 2009;57(5):355-360.

11. Cypel MC, Kasahara N, Atique D, et al. Quality of life in patients with glaucoma who live in a developing country. Int Ophthalmol. 2004;25(5-6):267-272. doi:10.1007/s10792-005-0077-9

12. Prabhu M, Patil SH, Kangokar PCR. Glaucoma awareness and knowledge in a tertiary care hospital in a tier-2 city in South India. J Sci Soc. 2013;40(1):3. doi:10.4103/0974-5009.109674

13. Mbadugha CA, Onakoya AO. The awareness, perceptions and experiences of primary open angle glaucoma patients in Lagos Nigeria. Sci Rep. 2014;4:7585. doi:10.1038/srep07585

14. Gyawali R, Sarkar N. Glaucoma awareness in a hospital presenting population in Eastern Nepal. J Glaucoma. 2014;23(9):594-598. doi:10.1097/IJG.0b013e31828700de

15. Livingston PM, Lee SE, De Paola C, Carson CA, Guest CS, Taylor HR. Knowledge of glaucoma, and its relationship to self-care practices, in a population sample. Aust N Z J Ophthalmol. 1995;23(1):37-41. doi:10.1111/ceo.1995.23.issue-1
16. Rewri P, Kakkar M. Awareness, knowledge and practice: A survey of glaucoma in North Indian rural residents. Indian $J$ Ophthalmol. 2014;62:482-486. doi:10.4103/0301-4738.132105

17. Alemu DS, Gudeta AD, Gebreselassie KL. Awareness and knowledge of glaucoma and associated factors among adults: a cross sectional study in Gondar Town, Northwest Ethiopia. BMC Ophthalmol. 2017;17(1):154. doi:10.1186/s12886-017-0542-z

18. Tenkir A, Solomon B, Deribew A. Glaucoma awareness among people attending ophthalmic outreach services in Southwestern Ethiopia. BMC Ophthalmol. 2010;10(1):17. doi:10.1186/1471-241510-17

19. Ogbonnaya CE, Ogbonnaya LU, Okoye O, Glaucoma Awareness K-AN. Knowledge, and attitude to screening, in a rural community in Ebonyi State, Nigeria. Open J Ophthalmol. 2016;06 (02):119-127. doi:10.4236/ojoph.2016.62017

20. Degineh H, Giorgis AT. Glaucoma awareness among ophthalmic patients at Menelik II Hospital, Addis Ababa, Ethiopia. Ethiop $J$ Health Dev. 2013;27(3):230-234.

21. Adegbehingbe BO, Bisiriyu L. Knowledge, attitudes, and self care practices associated with glaucoma among hospital workers in Ile-Ife, Osun State, Nigeria. Tanzan J Health Res. 2008;10:4.

22. De-Gaulle VF, Dako-Gyeke P. Glaucoma awareness, knowledge, perception of risk and eye screening behaviour among residents of Abokobi, Ghana. BMC Ophthalmol. 2016;16(1):204. doi:10.1186/ s12886-016-0376-0

23. Ziaei H, Katibeh M, Panah E, Moein H, Kalantarion M, Hosseini S. Knowledge and awareness of age related eye disease among people over 45 years of age in Tehran: a population-based survey. Bina $J$ Ophthalmol. 2012;18(1):57-65. doi:10.1094/PDIS-11-11-0999PDN

24. Cross V, Shah P, Bativala R, Spurgeon P. Glaucoma awareness and perceptions of risk among African Caribbeans in Birmingham, UK. Divers Equal Health Care. 2005;2:2.

25. YP MG J, Lin K, Trope GE. Glaucoma knowledge in a black community in Toronto. Int J Ophthalmol Eye Res. 2014;2(5):59.

26. Ntim-Amponsah CT, Winfried MA, Ofosu-Amaah S. Awareness and knowledge of glaucoma and other diseases associated with blindness in a Ghanaian community. Niger J Ophthalmol. 2004;12(2):50-54.

27. Thapa SS, Berg RV, Khanal S, et al. Prevalence of visual impairment, cataract surgery and awareness of cataract and glaucoma in Bhaktapur district of Nepal: the Bhaktapur Glaucoma study. BMC Ophthalmol. 2011;11(1):2. doi:10.1186/1471-2415-11-2

28. Dandona R, Dandona L, John RK, McCarty CA, Rao GN. Awareness of eye diseases in an urban population in southern India. Bull World Health Organ. 2001;79(2):96-102.

29. Krishnaiah S, Kovai V, Srinivas M, Shamanna BR, Rao GN, Thomas R. Awareness of glaucoma in the rural population of Southern India. Indian J Ophthalmol. 2005;53(3):205-208. doi:10. 4103/0301-4738.16685

30. Mansouri K, Orgül S, Meier-Gibbons F, Mermoud A. Awareness about glaucoma and related eye health attitudes in Switzerland: a survey of the general public. Ophthalmologica. 2006;220 (2):101-108. doi:10.1159/000090574

31. Farooq S, Jaffar S, Kausar A. Determinants of glaucoma awareness in urban punjab. Pak Armed Forces Med J. 2015;65(5):591-594.

32. Costa VP, Spaeth GL, Maura S, Cordelia U, Paulo JV, Kara-Jose N. Patient education in glaucoma: what do patients know about glaucoma? Arq Bras Oftalmol. 2006;69(6):923. doi:10.1590/S000427492006000600024

33. Pujar C, Dasar L, Jayshree M, Patil MG, Shirbur PS. Evaluation of the awareness on glaucoma in a rural eye camp in North Karnataka, India. J Clin Diagn Res. 2012;6(7):1226-1228. 


\section{Publish your work in this journal}

Clinical Optometry is an international, peer-reviewed, open access journal publishing original research, basic science, clinical and epidemiological studies, reviews and evaluations on clinical optometry. All aspects of patient care are addressed within the journal as well as the practice of optometry including economic and business analyses. Basic and clinical research papers are published that cover

Submit your manuscript here: https://www.dovepress.com/clinical-optometry-journal all aspects of optics, refraction and its application to the theory and practice of optometry. The manuscript management system is completely online and includes a very quick and fair peer-review system, which is all easy to use. Visit http://www.dovepress.com/ testimonials.php to read real quotes from published authors. 